Fecha de recepción: marzo 2012 Fecha de aceptación: junio 2012 Versión final: marzo 2013

\section{Consideración de la escritura narrativa como indagación de sí mismo}

Gustavo Adolfo Aragón Holguín *

\begin{abstract}
Resumen: En este artículo se explora, desde el ángulo de la imaginación creativa, un tipo particular de ficción literaria: la auto-narración. Se propone que es un caso de lo que Paula Carlino denomina la escritura como emergencia de conocimiento, es decir, epistemológica (por oposición a la escritura como mnemotecnia o reproducción/ constatación de lo dado). Se exploran diversos casos de autores que escenifican fenómenos de comprensión que ocurren a los narradores auto-diegéticos, es decir, narradores que refieren su propia historia. Se examinan los casos del narrador Odiseo en Odisea de Homero, Marcel en, En busca del tiempo perdido de Marcel Proust, el narrador de Gran Sertón:Veredas de Joao Guimaraes Rosa y el proyecto e intencionalidad enunciativa que subyace la novela de Manuel Zapata Olivella Changó, el Gran Putas. A partir de cada caso examinado, se postulan algunas de las funciones que la autonarración puede tener. Finalmente, se plantea que esta opción de conocer es susceptible de incorporarse a las labores investigativas propias del hacer universitario.
\end{abstract}

Palabras clave: creatividad - didáctica - escritura - Literatura - narración.

[Resúmenes en inglés y portugués en la página 111]

${ }^{(*)}$ Licenciado en Literatura y Magíster en Literatura Colombiana y Latinoamericana (UV). Profesor de la Licenciatura en Literatura (UV). Profesor nombrado para los cursos de Literatura Clásica Griega, Literatura Clásica Latina y Narrativa Medieval y Renacentista. Orientador de la Práctica Docente y el Seminario de Trabajo de Grado (UV). Profesor de la Licenciatura para la Primera Infancia (USB-Cali), ofrece actualmente los cursos de Literatura Infantil y Didáctica de la Lengua.

\title{
Introducción
}

Que la escritura ha sido y será, dependiendo de los contextos y necesidades que determinan su emergencia en distintos ámbitos, algo diverso, polimorfo y dinámico, es el punto de partida de mi aproximación personal a esta indagación sobre la serie escritura / subjetividad / creatividad. Una rápida ejemplificación de esta aseveración la constituye la siguiente lista provisional: escritura es el acto que produce la carta de amor, la nota que remite la maestra a los padres de familia, el tratado formal con que los cursantes de programas académicos dan cuenta de su formación, la desgarradura que revela al doliente la ineluctable procedencia de sus dolores, la 
insufrible sentencia de muerte, la lista de compras, el graffitti y la marca comercial. Sus depositarias, las distintas formas o soportes expresivos, van desde el papiro al papel, pasando por los pixeles de la pantalla, la piedra, la madera y la epidermis, son vehículos de pensamiento.

Podemos ensayar una distinción básica, que se ha formulado en un útil informe de investigación de Paula Carlino, entre la escritura entendida como una suerte de registro o captura del mundo y la escritura como una forma de intelección, como una manera de conocer.

En el caso de la escritura, la representación más extendida la concibe como un canal para exteriorizar lo que se piensa y transmitir conocimiento (Alvarado y Cortés, 2000). Esta idea contrasta con su potencialidad epistémica, señalada por múltiples investigadores (por ejemplo, Cassany, 1997; Flower, 1979; Miras, 2000; Olson 1998; Ong, 1987; Scardamalia y Bereiter, 1985; Sommers, 1980). Para éstos, la escritura no es sólo un medio de registro o comunicación sino que puede ser un instrumento para acrecentar, revisar y transformar el propio saber (Carlino, 2005).

Me interesa referirme al segundo caso mencionado por Carlino y comentar una de las formas (o modos de ser) de la escritura: la escritura artística. En las líneas que siguen me propongo iniciar una caracterización de lo que podríamos denominar las ficciones novelescas y entenderlas como manifestaciones de creatividad que ponen de manifiesto, en la mimesis literaria, lo que ofrece una indagación subjetiva: la paulatina comprensión del sí mismo. En la perspectiva que propongo, la creatividad no resulta ex nihil y, en cambio, es producto de un repliegue imaginativo que opera por imágenes que se rescatan de una historia que, si bien se puede la puede conocer, no necesariamente supone una comprensión. Sigo en esto el parecer de sir Kenneth Robinson cuando afirma lo siguiente:

La imaginación es la capacidad más extraordinaria de los seres humanos, la que nos permite traer a la mente todo aquello que no está disponible para ser captado por nuestros sentidos. Con la imaginación podemos revivir el pasado, ponernos en el lugar de otra persona y sentir empatía con ella. O anticipar el futuro; no preverlo, pero sí anticipar distintas posibilidades. Todo lo distintivamente humano proviene del poder de la imaginación. La creatividad consiste en poner la imaginación a trabajar (Robinson, 2006).

Convocaré la palabra de algunos personajes de novelas de diversas coordenadas culturales y geográficas, procurando soslayar la polémica de si el narrador de una novela debería o no identificarse con el autor de la misma 1 . Anuncio, pues, los personajes que he invitado a este texto. En primer lugar quiero recordar la manera como un hombre que es Nadie llega a ser Alguien, un Alguien llamado Odiseo, el protagonista de la epopeya homónima de Homero. Luego daré un salto para repasar la angustia frente a la muerte que experimenta un tal Marcel, quien encuentra en el acto de novelar-se su única alternativa para conjurarla; el personaje proviene de una novela titulada En busca del tiempo perdido, del francés Marcel Proust. Otro salto nos llevará al sertón del nordeste de Brasil, a una habitación en penumbra, donde un ex yagunzo (una suerte 
de ex bandolero, ya casi anulado por el tiempo y el olvido) relata para otro su vida y paulatinamente la va comprendiendo. Se llama Riobaldo, y conjuga en su nombre las aguas que fluyen (o que fluyeron) y el desierto baldío del presente; es la voz perenne del romance Gran Sertón: Veredas, de Joao Guimaraes Rosa. El viaje culmina con la alusión un personaje de estas tierras: el anónimo yo poético que anuncia para el muntu, el hombre americano, la maldición de Changó, en la novela Changó, el gran putas del escritor afrocolombiano Manuel Zapata Olivella.

\section{Odiseo ante los feacios o la escritura como recuperación de la travesía}

Ulises, del linaje de Zeus, Ulises, fecundo en $\operatorname{ardides}^{2}$, ha escapado del abrazo amoroso de la ninfa Calipso. Abandonó en mínima barca la isla Ogigia y el airado Poseidón ha hecho de las suyas en su periplo por la mar: ha desatado terribles tormentas, vientos huracanados y lluvias interminables. Así, náufrago, es como lo encuentra Nausicaa, la princesa de los Feacios, ese pueblo de constructores de barcos y danzarines; la barba hirsuta, el cuerpo lacerado, el ánimo sombrío, nunca ha habido un mejor nombre para él ése con que engañara a Polifemo: Ulises es ahora Nadie. Ante sus anfitriones pide a Demódoco, el bardo de la corte, que cante una historia en particular.

- ¡Demódoco ¡ Yo te alabo más que a otro mortal cualquiera, pues deben haberte enseñado la Musa, hija de Zeus, o el mismo Apolo, a juzgar por lo primorosamente que cantas el azar de los aqueos y todo lo que llevaron a cabo, padecieron y soportaron, como si tú en persona lo hubieras visto o se lo hubieses oído referir a alguno de estos. Mas, ea, pasa a otro punto y canta cómo estaba dispuesto el caballo de madera construido por Epeo con la ayuda de Atenea; máquina engañosa que el divinal Ulises llevó a la acrópolis, después de llenarla con los guerreros que arruinaron Troya (Homero, 1988).

En el mundo de Ulises, el universo al que se refiere la épica homérica, los aedos constituyen una clase social, la de los demiurgos: junto a los augures o adivinos, los sacerdotes, los médicos y los heraldos son quienes dominan una tejné, si, pero que posee una cualidad más intelectual, si bien se trata de una habilidad al servicio de la comunidad. Los aedos, en particular, tienen un rasgo en particular: su oficio, su tejné, resulta de una manía, de una locura o inspiración que es entregada por los dioses, no deviene de un aprendizaje. En el fragmento citado, Ulises no sólo establece una relación entre el arte de Demódoco con Zeus o la Musa, sino que también destaca que el aedo no tiene que haber vivido u oído las cosas para referirlas; le son dadas. ${ }^{4}$ Así, no es relevante para ese momento saber si el aedo es, además de un cantor, un compositor o un poeta, en el sentido contemporáneo de ser un creador. A esto se refiere Rodríguez Adrados:

No era la originalidad aquello que en primer término buscaban ni el aedo ni su público. Buscaban en primer término contar la verdad sobre el pasado y dar gloria ( kléa) a las acciones de los héroes antiguos, transmitiendo a los hombres la verdad que les inspiraban las Musas (Rodríguez Adrados, 1984). 
En cambio, y sobre este aspecto llamo la atención, Odiseo se dirige a continuación ante sus anfitriones y relata su propia historia, la ofrece como solo él podría ofrecerla ya que, a la sazón, todos sus compañeros, los testigos de los eventos, han muerto. Tan solo contamos ahora con su palabra sobre sí. Estas palabras, esta narración, esta auto-narración, es la odisea en sí misma. La odisea entendida, como aún lo hacemos, como un trasegar, un errabundar, pero que en algún momento ha de ser tramada con palabras. Es lo que hacemos día a día cuando volvemos del cine, cuando contamos las travesuras, cuando instigamos desde el chisme, cuando admitimos el pecado. En el caso de Odiseo, el personaje, le es restituido un ser perdido en la marea furiosa de Poseidón, quien ha castigado con dura mano su hybris, su arrogancia, explícita al jactarse de su ingenio ante el cegado Polifemo, a quien previamente ha dicho que su nombre es NADIE. Así, postulo desde el relato de Odiseo una primera forma de indagación narrativa: recuperar la travesía, para entregarla de manera febril, regocijada o temerosa a un otro y, en ese instante, de manera inevitable, a sí mismo.

\section{Marcel Proust o la escritura como sortilegio ante la muerte}

Preludio autobiográfico. Por los años en que debía de haberme ya graduado de la Licenciatura en Literatura que cursé como pregrado, comencé a ser acosado por mis amigos y mi familia con un coro infernal que me recordaba aquel cuadro sobre la Erinias persiguiendo al matricida Orestes: Escribe la monografía, escribe la monografía, escríbela... pero ya. Y nada: la tenía "clara" en la cabeza pero no había ningún paso al acto escritural efectivo. Postergué lo postergable; procastiné; llegué incluso a pensar que el obstáculo era tan enorme que era mejor dejar las cosas así, llegué casi a convencerme que el tiempo de la escritura llegaría por sí mismo.

Hubo entonces un acontecimiento que me disparó a iniciar mi labor: mi directora de monografía anunció con gracia y donaire que si no escribía dentro de un plazo determinado debería tomar materias de nuevo. Y ahí fue Troya, o mejor, ahí fue Proust y mi lectura de En busca del tiempo perdido.

¿Qué ocurre en ese libro que importe a esta reflexión? La novela hace referencia a un hombre que, al cabo de su vida, al cabo de su niñez y juventud, presintiendo la muerte, siente que ha perdido el tiempo, siente que ha intentado infructuosamente producir su obra pero que distintas circunstancias (amores, desamores, de amadas cautivas y fugitivas, amigos encantadores y de clase noble, insufribles arribistas, bailes de sociedad de galante, reposadas contemplaciones de catedrales) lo han distraído de su labor como artista de la palabra. Y llega entonces la muerte, después de la cual el tiempo, y todo, estará irremediablemente perdido. A menos que escriba... a menos que emerja un libro que sea capaz de confrontar el Tiempo.

Además, esta idea del Tiempo tenía para mí otro valor: era un acicate, me decía que ya era hora de comenzar si quería conseguir lo que a veces sintiera en el transcurso de mi vida, en breves fogonazos, camino de Guermantes, en mis paseos en coche con mademe de Villeparisis, y que me hizo considerar la vida como digna de ser vivida. Cuánto más me lo parecía ahora que creía poder 
esclarecerla, esa vida que vivimos en las tinieblas, traída a la verdad de lo que era, esa vida que falseamos continuamente, por fin realizada en un libro. Qué feliz sería, pensaba yo, el que pudiera escribir un libro así, qué labor ante él (Proust, 1979).

Ocurre entonces esa porción maravillosa de literatura que es la escena de la magdalena. Marcel, al mojar una especie de pandero en su té, recupera con su memoria involuntaria y de manera total, con toda la potencia sensorial de la cual el acto voluntario de recordar no participa, recupera, digo, un trozo de su infancia. Se da cuenta que debe atesorarlo con la palabra, comprende que esa escritura lo salva, que es su tiempo recobrado. Y escribe.

De Proust rescato, entonces, la idea de la escritura como un desafío a la disolución del ser, como un reto mismo a la muerte, acaso un sortilegio. Bécquer ha llamado a esto sinfronía, la capacidad que tiene una obra de hablarle a muchas generaciones y a muchas latitudes, Borges nos habla de la "verde eternidad" de las Itacas. Yo veo aquí una especie de erotismo locuaz que triunfa sobre un tanatismo silente: glosando a Bataille, un insistir sobre la vida, hasta en la muerte.

\section{Riobaldo o la escritura como descubrimiento de sí}

Les invito ahora a una casa derruida por el tiempo y por la ausencia. Esa casa está perdida en medio de las veredas del desierto nordestino de Brasil, en el sertón árido y tenaz, tierra de bandoleros o yagunzos, de cuatreros, de centauros curtidos por el sol, armados de machetes y animados por sus códigos de honor (que nos recuerdan la aristeia de los héroes homéricos, el bushido del samurái, la omerta de la mafia siciliana). Y en esa casa, en un cuarto, hablando con un hombre llegado de la ciudad, a quien le interesa de diversas maneras la historia que escucha, hay un ex yagunzo, un ex bandolero. El tiempo lo ha devorado y lo ha regurgitado. Ahora yace postrado y con verbo singular, en que no siempre encontramos el orden de la lengua estándar o del idioma oficial, y en cambio sí la palabra vital y cercana, el titubeo, el olvido parcial y el reencuentro con las palabras que van desenterrando el pasado, con esa palabra que serpentea entre las veredas de la memoria, el ex yagunzo actualiza su drama amoroso.

He aquí un ejemplo de esa palabra...

Al principio, yo hacía y revolvía, y pensar, no pensaba. No administraba el tiempo. Viví sacando lo difícil de lo difícil, el pez vivo del asador: quien está a las duras, no fantasea. Pero ahora, con la holganza que se me llega, y sin pequeños desasosiegos, ando rumia que rumia y le he tomado el gusto a especular ideas. El diablo ¿existe y no existe? Doy mi palabra. Abrenuncio. Estas melancolías. Usted puede verlo: existe la cascada... ¿y entonces? Pero, una cascada es un barranco de tierra y agua cayendo por él, retumbando; usted consume esa agua, o se deshace el barranco ¿queda algo de la cascada? Vivir es un negocio muy peligroso (Guimaraes, 2000). 
No lo voy a contar, claro, para no arruinar el secreto a quienes se animen a leer la obra de Guimarães. Solo diré que es un drama amoroso potente, diverso, plétora de ternura, excitante, portentoso. Acaso el motivo de la dama guerrera medieval esté por esos lados;pero también, porque esta obra logra, refiriéndose a lo local, alcanzar lo universal.

¿Y qué le ocurre a Riobaldo al contar? Le ocurre que se va comprendiendo, se va entendiendo. Todo eso que vivió, que se presentaba como un enigma, como algo incomprensible, una vez tomada la distancia, en plena discontinuidad, se llega a entender: es la narración lo que le permite descubrirse, ante sí y ante el otro. Y ese velo descubierto tal vez le proporcione felicidad, regocijo, tal vez sean otras las especies: dolor, lamento, nostalgia. Pero, en cualquier caso, la revelación -la epifanía la llamaría Joyce- sobreviene como un acontecimiento de lenguaje.

Y me cierro, aquí, mire y vea. Esto no es lo de uno relatar pasajes de su vida, con toda admiración. Cuento lo que fui y vi, al levantarse el día. Auroras. Cierro. Ya ve usted. Lo he contado todo. Ahora estoy aquí, casi un barranquero. Para la vejez voy, con orden y trabajo. ¿Sé de mí? Cumplo. El río de San Francisco -que de tan grande se comparece- lo que parece es un árbol grande, en pie, enorme... Amable usted me ha oído, mi idea se ha confirmado: el diablo no existe. ¿Pues no? Usted es un hombre soberano, circunspecto. Amigos somos. Nonada. El diablo no hay. Es lo que yo digo, si hubiese... Lo que existe es el hombre humano. Travesía (Guimaraes, 2000).

Resumiendo, escribimos (también) para lanzarnos al vacío más recóndito: el de nuestra propia e incomprendida existencia. Lo que acabo de escribir me encauza hacia ese poema del poeta colombiano José Asunción Silva (1996):

Las cosas viejas, tristes, desteñidas, Sin voz y sin color, saben secretos

De las épocas muertas, de las vidas Que ya nadie conserva en la memoria, $\mathrm{Y}$ a veces a los hombres, cuando inquietos

Las miran y las palpan, con extrañas

Voces de agonizante, dicen, paso,

Casi al oído, alguna rara historia

Que tiene oscuridad de telarañas,

Son de laúd y suavidad de raso.

Arpa olvidada que al sonar, te quejas;

Barrotes que formáis un monograma Incomprensible en las antiguas rejas, El vulgo os huye, el soñador os ama $\mathrm{Y}$ en vuestra muda sociedad reclama Las confidencias de las cosas viejas! El pasado perfuma los ensueños Con esencias fantásticas y añejas 
Y nos lleva a lugares halagüeños

En épocas distantes y mejores;

Por eso a los poetas soñadores,

Les son dulces, gratísimas y caras,

Las crónicas, historias y consejas,

Las formas, los estilos, los colores,

Las sugestiones místicas y raras

Y los perfumes de las cosas viejas

(Silva, 1996).

Y esto ocurre en esa especie de almacén de recuerdos y vejeces, que yacen lámina por lámina (la metáfora es de Michael Ende, en su Historia Interminable) aguardando nuestro rescate.

\section{La resistencia frente a la barbarie: el muntú en la diáspora}

Changó, el gran putas (1960), título de novela mestizo según la profesora Dorita Piqueiro, es un texto eje dentro de la obra del novelista colombiano Manuel Zapata Olivella, quien tuvo distintos intereses en su obra literaria e intelectual, pero entre ellos el tema de la identidad afro en América resulta ser decisivo y, por lo visto, emblemático desde las miradas internas y externas sobre el tema. Esta obra está conformada por cinco secciones, que ofrecen una visión del fenómeno del esclavismo en América desde su inicio hasta nuestros días. Llama la atención la manera como es anunciada en el paratexto titulado Al compañero de viaje. Desde ahí se puede notar que las operaciones narrativas no son planas o mondas: el autor empírico reclama del lector (el compañero de viaje) distintas disposiciones antes de comenzar a leer. Por una parte insta a que se asuma el lugar del otro, en este caso el lugar del hombre encadenado en la nao negrera, pero señala que, aun así, el lector ha de sentirse libre "aunque te aten las cadenas sigue hazte niño y desnudo, renuncia a la bitácora, entrégate a Elegbá”.

Como se ha dicho, la novela (así lo declara el proemio: "sube a bordo de esta novela") se publicó en los años 60, época que corresponde, dentro del periplo personal de Zapata Olivella, a su plena intención de hacer evidente el carácter tri-étnico del pueblo colombiano, eso sí, anclando su indagación de manera preferente en el componente afro. Entendida como forma textual, la novela posee un carácter proteíco, en el sentido en que permite la convergencia de diversos tipos textuales, aunque sea la narración en prosa la modalidad anudante y más frecuente. En este caso, tenemos un caso elocuente de esa diversidad. Así lo señala Piquero, cuando presenta su traducción a la lengua francesa.

Imposible exigir que Changó, el Gran Putas cuadre con estrictos cánones narrativos, pues se inaugura en verso, con inesperado cariz de epopeya. Estructura y escritura reflejan semejante inauguración, confiriendo al texto narrativo dimensión épica (Piquero, 1991, p. 34).

La primera parte de la novela está conformada por una serie de poemas. La sección inicial de esta parte se titula La tierra de los Ancestros, subtitulada Los Orichas y luego Deja que cante la kora. Un yo poético (a la manera de un narrador auto-diegético) se sitúa como enunciador, se trata de Ngafúa, hijo de Kissi-Kama y dirige su discurso a un enunciatario que, verosímilmente, 
es el Muntu o el mismo Kissi-Kama.El conjunto de estos poemas posee un carácter épico y una importante materia referencial de los mismos es la mitología yoruba.

Aclaremos desde ya que decir carácter épico (o cariz o matiz o resonancia) no equivale, precisamente, a proponer que hay aquí un texto épico, propiamente dicho, o que hay aquí mitos. Ni mito ni epopeya y, en cambio sí una suerte de, para utilizar la expresión acuñada por Mario Vargas Llosa, novela total. Que parcialmente convoca referencialidades de tipo mitológico, con propósitos concretos, apropiándose en algunos momentos del formato de la épica. Otro tanto se puede afirmar de Eneida de Virgilio, texto que se levanta no sólo sobre las invenciones estilísticas y estructurales de Homero (que, a su vez, constituye el tránsito de la oral poetry a las formas letradas llamadas cultas) sino que también bebe tanto en la lírica popular como en la llamada lírica culta, los aportes de los tragediógrafos e, incluso, en las formas narrativas de la denominada novela bucólica.

En un hermoso texto, titulado Érase una vez... el universo, los dioses, los hombres, que surge de un acto amoroso de entrega a sus nietos de su materia central de indagación (la mitología griega), Jean-Pierre Vernant anuncia, en la perspectiva de comprender el legado helénico, la necesidad del estudio comparado.

En efecto, "mito" y "mitología" son palabras griegas vinculadas a la historia y a ciertos rasgos de esta civilización. ¿¿Se deriva de ahí que no son pertinentes por fuera de ella, que el mito y la mitología no existen sino bajo la forma y el sentido griegos? La verdad es lo contrario. Para comprender las leyendas helénicas es necesario compararlas con los relatos tradicionales de otros pueblos, correspondientes a épocas y culturas muy diversas, sean la China, la India y el Oriente próximo antiguos, la América pre-colombina o África (Vernant, 2008, p. 9).

Nos parece ver en las palabras del intelectual francés un aspecto importante del proyecto de Zapata Olivella, que, como antes dijimos, cifra una importante dimensión de su labor como antropólogo y artista en la percepción de la interculturalidad propia del mestizo colombiano. Creemos que la operación que culmina en Changó, el Gran Putas consiste en una búsqueda de comprensión del ser latinoamericano que, por diversas razones inicia en el continente africano (particularmente en las tradiciones de las comunidades yoruba) pero que no se queda ahí, que trasciende y propone conexiones interculturales de peso, invisibilizadas por la cultura oficial. Así, se destaca el papel que tiene el mito en la cultura. Y con esa materia se funda una lírica que tiene otro propósito: la comprensión esperanzadora. Otro teórico del campo del mito, Mircea Elíade, anuncia que su reflexión tendrá en cuenta las sociedades en las que el mito tiene -o ha tenido hasta estos últimos tiempos- "vida", en el sentido de proporcionar modelos a la conducta humana y conferir por eso mismo significación y valor a la existencia (1991, pág. 8). Un poco más adelante, precisa, aludiendo su obra El mito del eterno retorno, que la función principal del mito es revelar los modelos ejemplares de todos los ritos y actividades humanas significativas. $\mathrm{Y}$ este tema de encontrar sentido a la existencia se revela como algo urgente y dramático ante la dimensión de sinsentido con que se ofrece el holocausto esclavista del siglo XVI en África Oriental. ¿Qué otra noción oponer a la barbarie que no sea la de destino, es decir, aquello preestablecido, ineluctable, externo al sujeto? Es, quizá, lo único que confiere sentido a sin-sentido: el anagramático destino. 
Los "cargo cults" de Oceanía son cultos "proféticos y milenarios" que proclaman la inminencia de una era fabulosa de abundancia y beatitud. Los indígenas serán de nuevo los señores de sus islas y no trabajarán más, pues los muertos volverán en sus magníficos navíos cargados de mercancías, semejantes a los cargos gigantescos que los Blancos acogen en sus puertos. Ahora bien, todos estos actos y creencias se explican por el mito del aniquilamiento del Mundo seguido de una nueva Creación y de la instauración de la Edad de Oro, mito que nos ocupará más adelante (Elíade, 1991, p. 9).

Rescatemos, de Elíade, aquella definición que ofrece y que, por su carácter general, es decir, por su posibilidad de abarcar distintas representaciones míticas, le resulta, según sus palabras, menos imperfecta.

El mito cuenta una historia sagrada: relata un acontecimiento que ha tenido lugar en un tiempo primordial, el tiempo fabuloso de los "comienzos". Dicho de otro modo: el mito cuenta cómo, gracias a las hazañas de los Seres Sobrenaturales, una realidad ha venido a la existencia, sea ésta la realidad total, el Cosmos, o solamente un fragmento: una isla, una especie vegetal, un comportamiento humano, una institución. Es, pues, siempre el relato de una "creación": se narra cómo algo ha sido producido, ha comenzado a ser (Elíade, 1991, p. 12).

Con lo dicho planteamos nuestra última comprensión de estas auto-narraciones. No hay en la obra de Zapata Olivella, en rigor, mito. Hay, en cambio, un cuidadoso procedimiento de alusión mitológica al servicio de una lectura propositiva, intencionada y esperanzadora a la vez de la diáspora. Esto ocurre cuando un autor se plantea o se asume como el narrador no ya de sí mismo sino como el portavoz de un pueblo. Y no escribe para sumirse en la desgracia de lo vivido: se escribe para ofrecer esperanza, vitalidad para cambiar, para resistir.

\section{Conclusiones}

Nuestros dispositivos escolares siguen confluyendo en la escritura. Su prestigio en nuestra cultura académica, es, por lo visto, incontestable. Esto es curioso; gran parte de lo que hacemos tanto en la formación de pregrado como la de posgrado consiste en actos orales; en el peor de los casos, de discursos que son enunciados para enunciatarios que están condenados a incorporarlos y a repetirlos (como señala CarlosSkliar, discursos orales que buscan explicar, completar, corregir al otro); en el mejor de los casos, se trata de conversaciones. No obstante, llegada la evaluación, que al parecer constituye y/o valida indefectiblemente al dispositivo escolar, la evidencia es siempre textual: un examen, un ensayo, un ensayito, tres cuartillas, un test de preguntas cerradas, una monografía, una tesis. Y dicho sea de paso (aunque de manera rotunda): esa modalidad es requerida y con lamentable frecuencia no se la propone como uno de los aprendizajes propios del proceso formativo, de la malla curricular. Oscila entre el misticismo (algún numen o dios que le sea propicio le hará escritor con un toque de varita mágica, tal vez Prometeo o alguna de las nueve musas) o bien es supuesta en los estudiantes a la brava y en retrospectiva. 
Dicho lo anterior, en un esfuerzo por problematizar el tema de la escritura en nuestros entornos universitarios, me aferro a la esperanza, al horizonte esperanzador. Quiero creer que propuestas como incorporar una auto-eco-biografía en la obra de conocimiento del cursante de magister, resuelven, al menos responden creativamente a la necesidad de que las tesis sean algo más que el requisito final y constituyan emergencias poiésicas de sujetos políticos en escritura y en gesto de indagación sostenida, alerta e inteligente. Pero, insisto, esta caracterización de la forma textual (en otras palabras, afirmar que la tesis podría ser de esta manera en vez de esa otra manera que ha sido descartada como efecto de la labor crítica) no es suficiente. Propuestas como la de Jorge La Rosa y Carlos Skliar, que entienden la educación como una especie de conversación pueden llegar a constituir conversaciones, desatan, desencadenan actos de escritura a la luz de lo que por aquí ${ }^{3}$ denominamos problema de conocimiento. Y esas escrituras parciales, provisionales, perfectibles, dan lugar a nuevas conversaciones, a emergencias de conocimiento. Opto por ofrecer estas palabras como un aporte mínimo pero sentido y honesto a esa metaconversación que termina en el papel. Creo que la lectura intencionada de algunas ficciones literarias, en particular aquellas que poseen la configuración que he comentado, auto-narraciones cuyo efecto es revelar al responsable del decir aspectos de sí mismo que resultan inéditos, sorprendentes, inopinados, insoportables o regocijantes, ofrece una valiosa atalaya para volver sobre sí mismo en términos de escritura.

\section{Notas}

1. Esta polémica, por cierto, resulta impertinente para esta aproximación... ¿ ¿debería añadir que me resulta impertinente del todo, si considero la novela como un hecho estético? Me explico, de la novela María (cuyo narrador es el personaje Efraín, es decir, la trama de lenguaje que el hombre Jorge Isaacs eligió como estrategia narrativa para referir la historia que quiso contar) me importa más el tejido verbal que pone en evidencia ideas sobre el mundo que la oscura circunstancia (con frecuencia usufructuada por entidades de turismo) de si las trenzas que hay en un cuarto de la Hacienda El paraíso fueron o no de María.

2. El adjetivo utilizado en la lengua original, polytropos, es anfibológico; puede designar "el de los muchos caminos", es decir, el carácter "andariego" del héroe, pero también se refiere a sus muchas "mañas", es decir, los diferentes recursos con que enfrenta la adversidad.

3. Este texto es una elaboración de una intervención oral ofrecida en el marco . II Encuentro Nacional de Educación: Desarrollo Humano organizado por la Facultad de Educación de la Universidad de San Buenaventura. Agosto 12, 13 y 14 de 2009. Cali, Colombia. De ahí la referencia a los aportes, también orales en ese evento, de Carlos Skliar. De ahí, también e inevitablemente, el carácter un poco oral de estas líneas. 


\section{Referencias Bibliográficas}

Carlino, P. (2005). Representaciones sobre la escritura y la forma de enseñarla en las universidades de América del Norte. En: Revista de Educación No. 336. Madrid.

Elíade, Mircea. (1992). Lo sagrado y lo profano. Barcelona: Colección Labor. (1991). Mito y realidad. Barcelona: Colección Labor.

Guimarães Rosa, J. (2000). Gran Sertón: Veredas. Madrid: Alianza Editorial.

Homero. (2008). Odisea. Trad. de Segalá, L. y Estela (1927). Madrid: Editorial Cátedra.

Proust, M. (1979). El tiempo recobrado de En busca del tiempo perdido (Tomo VII). Trad. de Berges, C. Madrid: Alianza Editorial.

Robinson, K. (2006). Conferencia organizada por TED (Ideas worth spreading) en Montreal California. Disponible en http://www.ted.com/talks/ken_robinson_says_schools_kill_creati vity.html

Rodríguez Adrados, J. (1984). Introducción a Homero (con Manuel Fernández Galiano, Luis Gil y José Lasso de la Vega). Barcelona: Editorial Labor.

Silva, J. A. (1996). Obra completa. Madrid: Ediciones de Centenario. Casa de Poesía Silva.

Vernant, J.-P. (2008). Érase una vez... el universo, los dioses, los hombres.

Zapata Olivella, M. (1991). Changó, el gran putas. Introducción y notas de Dora Piquero. Bogotá.

Summary: This paper explores, from the standpoint of creative imagination, a particular type of fiction: self-narration. It is proposed that is a case of what Paula Carlino calls the emergence of writing as knowledge, ie, epistemological (as opposed to writing as a mnemonic or reproduction / verification of the given). We explore several cases of authors that stage of understanding phenomena that occur at the self-diegetic narrators, ie narrators who relate their own story. It examines the cases of the narrator Odysseus in Homer's Odyssey, Marcel, In Search of Lost Time by Marcel Proust, the narrator of Gran Sertao: Veredas, by Joao Guimaraes Rosa and the project and intentionality underlying declarative novel Manuel Zapata Olivella, Xangó, the Great Whores. From each case examined, are postulated some of the functions that selfnarrative may have. Finally, we propose that this knowing option could be included in the investigative university work

Key words: creativity - didactics - Literature - narrative - writing.

Resumo: Neste artigo se explora, desde o ângulo da imaginação criativa, um tipo particular de ficção literária: a auto-narração. Se propõe que é um caso do que Paula Carlino denomina a escritura como emergência de conhecimento, é dizer, epistemológica (por oposição à escritura como mnemotecnia ou reprodução / constatação do dado). Exploram-se diversos casos de autores que representam fenômenos de compreensão que acontecem aos narradores auto-diegéticos, é dizer, narradores que referem sua própria história. Examinam-se os casos do narrador Odiseo em Odisea de Homero, de Marcel em Em busca do tempo perdido de Marcel Proust, o narrador de Grande Sertão: Veredas, de João Guimarães Rosa e o projeto e intencio- 
nalidade enunciativa que subjaze a novela de Manuel Zapata Olivella Xangô, o grande fodão. A partir de cada caso examinado, se postulam algumas das funções que a auto-narração pode ter. Finalmente, se expõe que esta opção de conhecer é susceptível de incorporar-se às lavores de pesquisa próprias do âmbito universitário.

Palavras chave: criatividade - didática - escritura - literatura - narração. 